\title{
Menemen Koşullarında Pamuk Yetiştiriciliğinde Uygulanan Farklı Toprak İşleme Yöntemlerinin Enerji Verimliliği ve Kullanım Etkinliğinin Belirlenmesi
}

\section{Tuncay TOPDEMIR ${ }^{* 1}$ (D), Mustafa Bülent COŞKUN}

\author{
${ }^{1}$ Uluslararası Tarımsal Araştırma ve Eğitim Merkezi Müdürlüğü Menemen Izmir \\ ${ }^{2}$ Aydın Adnan Menderes Üniversitesi Ziraat Fakültesi Biyosistem Mühendisliği Bölümü Tarımsal Enerji Sistemleri \\ Anabilim Dalı-AYDIN
}

Öz: Bu çalışmada pamuk üretiminde farklı toprak işleme yöntemlerinin uygulandığı parsellerin enerji ve maliyet analizleri üzerine araştırma yapılarak, üretimdeki girdilerin birim alan başına enerji eşdeğerleri, elde edilen ürünün enerji verimliliği, toplam maliyet ve kar değerleri hesaplanmıştır. Araştırmada kullanılan veriler, dört farklı yöntemde 3 tekerrürlü olarak yürütülen deneme parsellerinden elde edilmiştir.

Çalışmada en yüksek enerji girdisi geleneksel toprak işleme yönteminde, en düşük enerji girdisi ise doğrudan ekim yönteminde gerçekleşmiştir. Enerji çıktıları incelendiğinde ise en yüksek enerji çıktısı verimin en yüksek olduğu geleneksel toprak işlemede en düşük enerji çıktısı da verimin en düşük olduğu doğrudan ekim yönteminde gerçekleşmiştir. En yüksek enerji oranı 4.38 ile geleneksel toprak işleme konusunda, sonra sırasıyla 3.99 ile azaltılmış toprak işleme 2 konusunda, 3.93 ile doğrudan ekimde gerçekleşmiştir. En düşük enerji oranı ise 3.72 ile azaltılmış toprak işleme 1 konusunda hesaplanmıştır.

Anahtar Kelimeler: enerji girdi-çıktı analizi, pamuk üretimi, maliyet analizi

\section{Determining Energy and Utilization Efficiency of Different Tillage Methods on Cotton Cultivation Under Menemen Plain Conditions}

\begin{abstract}
By carrying out energy and cost analyses on different agricultural practices applied in cotton cultivation, energy equivalence of inputs per unit area, energy efficiency of the crop, total costs and profit have been calculated. This data has been acquired from the experimental plots with three repetitions on four different methods.

The highest energy input is in Traditional Tillage, while the lowest is in Direct Drilling. When energy outputs compared, it's been understood that the highest energy output is in Traditional Tillage which has the highest yield and the lowest energy output is in Direct Drilling, which has the lowest yield.

According to the experiments the highest energy ratio is 4.38 in Traditional Tillage, followed by Reduced Tillage 2 with the ratio of 3.99 and Direct Drilling with the ratio of 3.93. The lowest energy ratio is found in Reduced Tillage 1 with the ratio of 3.72..
\end{abstract}

Keywords: energy input-output analysis, cotton production, cost analysis

GiRiş

Tarımsal ürünler 21. Yüzyılın karşımıza çıkan en önemli stratejik silahlarından biridir. Tarımın ülke ekonomimizde daha fazla yer tuttuğu bir sektör haline gelebilmesi için tarımsal üretimimizin hem miktarının, hem de kalitesinin artırılması büyük önem arz etmektedir. Tarımsal verimliliğin arttırılması, bunun sağlanabilmesi için gerekli olan en önemli unsurlardan biridir (Reis, 2016).

Girdi-çıktı miktarlarının oransal ifadesi, verimlilik olarak tanımlanabilir. Tarım alanında bahsedecek olursak eğer verimlilik, işgücü ve üretimde kullanılan tüm girdilerin birimlerine düşen miktar ile çıktı miktarları arasındaki ilişki olarak açıklanabilir. Ayrıca, üretim içinde bulunan etmenlerin üretim aşamasındaki etkenlik derecesini belirten bir kavram olan verimlilik, verimden ziyade herhangi bir etmenin üretebilme yeteneğini ortaya kayan bir kavram olarak karşımıza çıkmaktadır (Pirinççioğlu, 1988).

Tüm üretim alanlarında olduğu gibi Tarımsal üretimde de verimliliği belirlerken bazı unsurlar göz ardı edilmemelidir. $\mathrm{Bu}$ unsurlar, girdi fiyatları, ürün fiyatları, toprak, tohumluk sarfiyatı, sulama, ilaçlama, gübreleme, alet ve makine kullanımı, işgücü kullanımı, nakliye ve depolama ve ürünlerin pazarlanması, vergi, teşvik, destekleme alımları, işletmelerin kapasiteleri, arazilerin büyüklükleri ve çok parçalı olma durumu, arazinin sahiplik durumu gibi unsurlardır ve verimlilik bu unsurlara doğrudan bağlıdır. Bunun yanı sıra, kooperatif ve birlikler gibi üretici örgütlerine ortaklık durumu, eğitim seviyesi, ekonomik yapısı, yeni gelişme ve teknolojilere bakış açısı, araştırma olanakları, iklim ve toprak yapısı gibi faktörleri de içinde barındırmaktadır (Çelik, 2000).

Enerji etkenliğini arttırmak iki yolla mümkündür. Bunun için, ya verimin artırılması ya da girdilerin azaltılması gerekmektedir. Verimin artırılması sonsuz bir oran değildir. Ancak sınırlı değerler içerisinde mümkündür. Fakat girdilerin azaltılabilmesi, bilinçli bir şekilde kullanım ile mümkündür (Gözübüyük, 2012).

Toprak işleme uygulaması, toprağı korumak ve toprağın fiziksel, kimyasal ve biyolojik dengelerini düzenlemek

Sorumlu Yazar: tuncay.topdemir@tarim.gov.tr

Bu çalışma yüksek lisans tez ürünüdür.

Geliş Tarihi: 2 Temmuz 2018

Kabul Tarihi: 3 Mayıs 2019 
amacıyla yapılan bir işlemdir. Toprak işleme toprak verimliliğini korumak, erozyonu azaltmak, toprak sıkışıklığını önlemek, topraktaki flora ve faunayı korumak, bitkisel materyalin toprakla ilk buluştuğu andan itibaren gelişimini en iyi şekilde tamamlaması için uygun bir ortam oluşturmak ve çeşitliliğin muhafazasını sağlamak amacıyla yapılmaktadır (Aykas ve Önal, 1999).

Yoğun ve aşırı toprak işlemeyi beraberinde getiren geleneksel toprak işleme, tarla üstü trafiği arttırarak, toprak sıkışıklığına ve erozyona sebep olan bir unsur olarak karşımıza çıkmaktadır. Türkiye topraklarının \%34,4'ü, eğimi \%15 ile \%40 arasında değişen alanlardan oluşmaktadır. Bu durum erozyon tehlikesini arttırıcı bir durumdur (Korucu ve ark., 1998).

Geleneksel tarım, derin ve devirerek toprak işleme, anız yakılması gibi uygulamaları içerir. İçinde barındırdığı bu uygulamalar nedeniyle çevreye zararlı etkileri bulunmaktadır. Bu yöntemlerin zararlı etkileri bunlarla sınırlı değildir. Toprak sıkışıklığını arttırır, toprak bozulumlarına ve erozyona neden olur, aynı zamanda aşırı gübre ve ilaç sarfiyatı nedeniyle oluşan kalıntılar ile yeraltı sularına karışarak kirletilmesine de yol açarlar. Ayrıca aşırı ve yoğun toprak işleme tekniklerinin, atmosfere $\mathrm{CO}_{2}$ başta olmak üzere sera gazları salımını arttırarak küresel ısınmaya neden olduğu yapılan birçok araştırma sonucunda ortaya çıkmıştır. Çevreye verdiği olumsuz etkiler nedeniyle tarımın sürdürülebilirliğini de azaltır (Yalçın, 2003).

Pamuk, tarım sektöründe önemli endüstriyel bitkilerden biridir. Pamuk; tarımı ve sanayisi ile geniş bir iş alanı sağlarken lifi ile tekstil sanayisine, çiğiti ile yağ sanayisine, küspesi ile hayvancılık sektörüne, ihracatı ile dış ticaretimize çok önemli katkılar sağlayan bir üründür. Dokuma, iplik ve yağ sanayileri gibi birçok endüstriyel alanda vazgeçilmez hammadde kaynağıdır. Ülkemiz iç ve dış ticaretinde son derece büyük bir öneme sahiptir.

Pamuk; toprak isteği olarak, iyi drene olan, tınlı, tınlı-kum ve killi-tınlı alüviyal bünyeye sahip, pH'sı 6.5 - 7.5 arasında olan, iyi havalanan topraklarda çok iyi yetişebilmektedir. Türkiye'de pamuk üretimi yapılan bölgelerde yaygın olarak aynı tarlada sürekli pamuk yetiştirilmektedir. Bazı bölgelere az miktarda, pamuk-buğday-pamuk ekim nöbeti uygulanmaktadır (Anonim 2016).

$\mathrm{Bu}$ çalışmada, pamuk üretiminde farklı toprak işleme yöntemlerinin uygulandığı parsellerin, üretimde harcadıkları birim enerji miktarları, girdi çıktı analizleri ile belirlenmeye çalışılmıştır. Ayrıca her üretim sisteminin birim üretim alanı başına düşen tüm maliyetler hesaplanarak farklı toprak işleme yöntemlerine göre farklılıklar değerlendirilmiştir. Ulaşılan veriler sonucunda etkinliğin ve verimin olumsuz etkilendiği girdi unsurları tespit edilerek işletmelere etkinlik değerlerinin yükseltilmesi yönünde öneriler 8 sunulabilecektir. Mekanizasyon giderlerinin tüm giderler içerisindeki payı da her sistem için ayrı ayrı belirlenmiştir.

\section{MATERYAL VE YÖNTEM}

\section{Materyal}

Araştırmada pamuk çeşidi olarak GSN-12 seçilmiştir. GSN12 pamuk çeşidi çok verimli ve orta geçcidir. Çırçır randımanı yüksek, lif özellikleri yönüyle iyi durumdadır. GSN-12 çeşidi uzun boylu, bitki formu koniktir. Kozaları orta - büyük, boyuna kesiti genellikle eliptik, uçtaki çıkıntı orta ve koza dış yüzeyi gözeneklidir. Tohumlar orta irilikte, hav yoğunluğu orta, hav rengi gridir (Anonim, 2005).

Araştırma, Tarım ve Orman Bakanlığı, Tarımsal Araştırmalar ve Politikalar Genel Müdürlüğü Uluslararası Tarımsal Araştırma ve Eğitim Merkezinin Menemende bulunan deneme arazisinde gerçekleştirilmiştir. Menemen Ovası topraklarının büyük bir kısmı orta ve orta-ağır bünyeli olup eski Gediz yatağı kenarında genel olarak hafif, batıya doğru gidildikçe ağır karakter kazanmaktadır. Menemen Ovası aluviyal araziler ile koluviyal dağ eteklerini kapsamaktadır (TOPRAKSU, 1971).

Menemen Ovasında Akdeniz iklimi hakim olup yazları sıcak ve kurak, kışları ılık ve yağışlıdır (UTAEM, 2016).

Denemelerde Tarım ve Orman Bakanlığı Tarımsal Araştırmalar ve Politikalar Genel Müdürlüğü Uluslararası Tarımsal Araştırma ve Eğitim Merkezinde bulunan alet ve makinalar kullanılmıştır.

\section{Yöntem}

Deneme, tesadüf bloklarında şeritvari ekim deneme desenine uygun olarak, 4 farklı toprak işleme sistemi (Geleneksel Toprak İşleme yöntemi - GTi, Doğrudan Ekim Yöntemi - DE (Toprak İşlemesiz Yöntem), Azaltılmış Toprak İşleme Yöntemi 1 - AZ1, Azaltılmış Toprak İşleme Yöntemi 2 - AZ2) ile 3 tekerrürlü olarak yürütülmüştür. Parsel genişliği $2.8 \mathrm{~m}$, parsel uzunluğu $40 \mathrm{~m}$ olmak üzere her parsel $112 \mathrm{~m}^{2}$ olacak şekilde deneme kurulmuştur. Denemenin yürütüleceği parsellerden toprak işlemeden itibaren yapılan tüm işlemlere ait veriler hasat sonrasına kadar tutulmuştur. Yapılan mekanizasyon uygulamalarına ilişkin yakıt tüketimleri, gübre, tarımsal ilaç, tohum ve diğer tüm girdilere ait tüketim miktarları üzerinden enerji eşdeğerleri hesaplanarak farklı uygulamaların toplam enerji eşdeğerleri ve enerji kullanım etkinlikleri hesaplanmıştır.

\section{BULGULAR VE TARTIŞMA}

\section{Bulgular}

Araştırmada kullanılan her alet ve makinanın işgücü değerini veren etkin çalışma zamanını bulabilmek için ölçülen esas zaman (E), yardımcı zaman (YD) ve kaçınılması imkansız kayıp zaman (KI) değerlerinin toplamından yararlanılmıştır.

Denemede bulunan işgücü gereksinim ve iş başarıları Çizelge 1 de verilmiştir. Çizelge 1 incelendiğinde birim 
alanda harcanan efektif çalışma zamanı (EÇZ) en yüksek geleneksel toprak işleme yönteminde (GTi), en düşük ise doğrudan ekim (DE) yönteminde gerçekleşmiştir. Çizelge 1. Toprak işleme yöntemlerinin iş başarıları

\begin{tabular}{llllllll}
\hline & Alet ve Makinalar & E & YD & Ki & TZ & EÇZ & Fta \\
\hline GTi & Kulaklı Pulluk & 2.65 & 0.14 & 0.11 & 2.79 & 2.90 & 0.35 \\
& Diskli Tırmık & 0.35 & 0.06 & 0.02 & 0.41 & 0.43 & 2.35 \\
& Toprak Sürgüsü & 0.63 & 0.07 & 0.04 & 0.70 & 1.35 & 0.74 \\
& Pnömatik Ekim Makinası & 0.51 & 0.08 & 0.04 & 0.59 & 0.63 & 1.60 \\
\multirow{4}{*}{ AZ1 } & Ara Gübre Makinası & 0.51 & 0.06 & 0.03 & 0.57 & 0.60 & 1.66 \\
& Tarla Pülverizatörü & 0.25 & 0.05 & 0.01 & 0.30 & 0.31 & 3.18 \\
& Toplam & $\mathbf{4 . 9 0}$ & $\mathbf{0 . 4 6}$ & $\mathbf{0 . 2 5}$ & $\mathbf{5 . 3 6}$ & $\mathbf{6 . 2 1}$ & $\mathbf{0 . 1 6}$ \\
& Goble Diskaro & 0.58 & 0.06 & 0.03 & 0.65 & 0.67 & 1.49 \\
& Toprak Sürgüsü & 0.63 & 0.07 & 0.04 & 0.70 & 1.35 & 0.74 \\
& Pnömatik Ekim Makinası & 0.50 & 0.07 & 0.03 & 0.57 & 0.60 & 1.66 \\
& Ara Gübre Makinası & 0.50 & 0.06 & 0.03 & 0.57 & 0.60 & 1.68 \\
& Tarla Pülverizatörü & 0.24 & 0.05 & 0.01 & 0.29 & 0.31 & 3.27 \\
& Toplam & $\mathbf{2 . 4 6}$ & $\mathbf{0 . 3 1}$ & $\mathbf{0 . 1 4}$ & $\mathbf{2 . 7 7}$ & $\mathbf{3 . 5 3}$ & $\mathbf{0 . 2 8}$ \\
& Çizelli Rototiller & 0.32 & 0.06 & 0.00 & 0.06 & 0.07 & 2.45 \\
& Pnömatik Ekim Makinası & 0.51 & 0.08 & 0.04 & 0.59 & 0.63 & 1.60 \\
& Ara Gübre Makinası & 0.48 & 0.06 & 0.03 & 0.54 & 0.56 & 1.78 \\
& Tarla Pülverizatörü & 0.24 & 0.06 & 0.02 & 0.31 & 0.32 & 3.10 \\
& Toplam & $\mathbf{1 . 5 6}$ & $\mathbf{0 . 2 6}$ & $\mathbf{0 . 0 8}$ & $\mathbf{1 . 5 0}$ & $\mathbf{1 . 5 8}$ & $\mathbf{0 . 6 3}$ \\
& Doğrudan Ekim Makinası & 0.50 & 0.08 & 0.03 & 0.58 & 0.62 & 1.62 \\
& Ara Gübre Makinası & 0.52 & 0.06 & 0.03 & 0.58 & 0.61 & 1.63 \\
& Tarla Pülverizatörü & 0.25 & 0.06 & 0.02 & 0.31 & 0.32 & 3.10 \\
& Toplam & $\mathbf{1 . 2 8}$ & $\mathbf{0 . 2 0}$ & $\mathbf{0 . 0 8}$ & $\mathbf{1 . 4 7}$ & $\mathbf{1 . 5 5}$ & $\mathbf{0 . 6 4}$ \\
\hline
\end{tabular}

E: Esas Zaman (h.ha ${ }^{-1}$ )

Ki: Kayıp Zaman (h.ha ${ }^{-1}$ )

EÇZ: Efektif Çalışma Zamanı (h.ha ${ }^{-1}$ )

YD: Yardımcı Zaman (h.ha ${ }^{-1}$ )

TZ: Temel Zaman (h.ha ${ }^{-1}$ )

Fta: İş Başarısı (ha. $\mathrm{h}^{-1}$ )

En düşük işgücü gereksinimine ihtiyaç duyan tarla pülverizatörü, en yüksek iş başarısına sahiptir. Bunu 2.45 ha. $h^{-1}$ ile çizelli rototiller ve 2.35 ha. $h^{-1}$ ile diskli tırmık takip etmektedir. Buna göre hesaplanan iş başarı değerlerine bakıldığında, birim zamanda en fazla alan işlenen doğrudan ekim yönteminde iş başarısı 0.64 ha. ${ }^{-1}$ ile en yüksek bulunmuştur.

Yakıt tüketim miktarının belirlenmesi için depo tamamlama yöntemi uygulanmıştır. Her bir toprak işleme yönteminde kullanılan alet ve makinaların işletilmesi sırasında elde edilen yakıt tüketim miktarları toplanarak, hangi toprak işleme yönteminin birim alana ne kadar yakıt tükettiği hesaplanmıştır. Çalışmada eşit dozda gübre kullanılmıştır. Çizelge 2. Araştırmada kullanılan girdi miktarları

\begin{tabular}{|c|c|c|c|c|}
\hline Tarımsal Girdi Miktarları & GTi & AZ1 & AZ2 & DE \\
\hline Toprak İşlemede Yakıt Tüketimi $\left(\right.$ L.ha $\left.^{-1}\right)$ & 50.85 & 33.19 & 25.29 & 18.6 \\
\hline Gübreleme $\left(\mathrm{kg} \cdot \mathrm{ha}^{-1}\right)$ & 139.90 & 139.90 & 139.90 & 139.90 \\
\hline Zirai Mücadele $\left(\right.$ L.ha $\left.^{-1}\right)$ & 11.50 & 11.50 & 11.50 & 11.50 \\
\hline Sulama Suyu Miktarı $\left(\mathrm{m}^{3} \cdot \mathrm{ha}^{-1}\right)$ & $2,410.00$ & $2,410.00$ & $2,410.00$ & $2,410.00$ \\
\hline Elektrik (kWh.ha $\left.{ }^{-1}\right)$ & 453.81 & 453.81 & 453.81 & 453.81 \\
\hline Tohum (kg.ha ${ }^{-1}$ ) & 27.50 & 27.40 & 27.50 & 25.50 \\
\hline Verim $\left(\mathrm{kg} \cdot \mathrm{ha}^{-1}\right)$ & $5,764.25$ & $4,557.10$ & $4,721.40$ & $4,514.30$ \\
\hline
\end{tabular}

Toplam ve birim pamuk üretim alanı başına enerji tüketimleri hesaplanmış ve Çizelge 3 'de, enerji tüketim

bileşenleri toplu şekilde özetlenmiştir.
Beyaz sinek, yaprak biti, kırmızı örümcek gibi zararlılara karşı ilaçlama yapılmıştır. Bunun yanı sıra bodurlaştırıcı, koza açtırıcı ve yaprak dökücü özellikte bitki gelişim düzenleyici kullanılmıştır. Sulama suyu her toprak işleme yöntemi için eşit miktarda uygulanmış ve ölçülmüştür. Sulama kaynaklı elektrik tüketim miktarları kWh.ha ${ }^{-1}$ cinsinden hesaplanarak verilmiştir. Ekim sırasında her yöntem için kullanılan tohum miktarları tartılmış ve kg.ha ${ }^{-1}$ cinsinden hesaplanmıştır. Kullanılan tohum miktarları, doğrudan ekim yönteminde farklı bir makina kullanıldığından dolayı diğer yöntemlere oranla yaklaşık \%10 gibi daha az gerçekleşmiştir. Araştırmada kullanılan tüm girdiler Çizelge 2'de gösterilmiştir. 
Menemen Koşullarında Pamuk Yetiştiriciliğinde Uygulanan Farklı Toprak İ̧sleme

Yöntemlerinin Enerji Verimliliği ve Kullanım Etkinliğinin Belirlenmesi

Çizelge 3. Pamuk üretiminde enerji değerleri (MJ ha ${ }^{-1}$ )

\begin{tabular}{|c|c|c|c|c|}
\hline Girdiler & GTi & AZ1 & AZ2 & $\mathrm{DE}$ \\
\hline Tohum & 324.50 & 323.32 & 324.50 & 300.90 \\
\hline İş gücü & 620.08 & 601.57 & 598.00 & 604.90 \\
\hline Toprak işleme ve Ekim & 32.20 & 14.26 & 10.35 & 3.45 \\
\hline Gübreleme & 11.50 & 11.50 & 11.50 & 11.50 \\
\hline Sulama & 3.45 & 3.45 & 3.45 & 3.45 \\
\hline İlaçlama & 5.52 & 5.52 & 5.52 & 5.52 \\
\hline Çapalama & 564.65 & 564.07 & 564.42 & 578.22 \\
\hline Taşıma ve Pazarlama & 2.76 & 2.76 & 2.76 & 2.76 \\
\hline Toplam Gübre & $7,523.85$ & $7,523.85$ & $7,523.85$ & $7,523.85$ \\
\hline Nitrojen & $7,123.28$ & $7,123.28$ & $7,123.28$ & $7,123.28$ \\
\hline Fosfor & 400.57 & 400.57 & 400.57 & 400.57 \\
\hline Potasyum & -- & -- & -- & -- \\
\hline Toplam Kimyasal İlaç & $2,484.00$ & $2,484.00$ & $2,484.00$ & $2,484.00$ \\
\hline İnsektisit & $2,484.00$ & $2,484.00$ & $2,484.00$ & $2,484.00$ \\
\hline Herbisit & -- & -- & -- & -- \\
\hline Fungisit & -- & -- & -- & -- \\
\hline Su & $1,518.30$ & $1,518.30$ & $1,518.30$ & $1,518.30$ \\
\hline Yakıt-Yağ & $3,075.08$ & $1,996.03$ & $1,530.56$ & $1,132.20$ \\
\hline Toplam Enerji Girdisi & $15,545.81$ & $14,447.07$ & $13,979.21$ & $13,564.15$ \\
\hline \multicolumn{5}{|l|}{ Çıktılar } \\
\hline Toplam Enerji Çıktısı & $68,018.15$ & $53,773.78$ & $55,712.52$ & $53,268.74$ \\
\hline
\end{tabular}

Çizelge 3 incelendiğinde en yüksek enerji girdisi 15.5 bin $\mathrm{MJ.ha}^{-1}$ ile geleneksel toprak işleme yönteminde, en düşük enerji girdisi ise $13.5 \mathrm{MJ}^{-h^{-1}}{ }^{-1}$ ile doğrudan ekim yöntemin gerçekleşmiştir. Enerji çıktıları incelendiğinde ise, en yüksek enerji çıktısı yaklaşık 68 bin MJ.ha ${ }^{-1}$ ile verimin en yüksek olduğu geleneksel toprak işleme yönteminde, en düşük enerji çıktısı da yaklaşık 53 bin $\mathrm{MJ}$.ha ${ }^{-1}$ ile verimin en düşük olduğu doğrudan ekim yönteminde gerçekleşmiştir.

Pamuk üretiminde enerji analizi kapsamında yağ-yakıt tüketimi değerleri hesap ve ölçümler ile elde edilmiştir. Hesaplamalarda yağın enerji eşdeğeri $42.5 \mathrm{MJ}^{-1}{ }^{-1}$, dizel yakıt enerji eşdeğeri, ise $56.31 \mathrm{MJ}^{-1}$ olarak alınmıştır (Singh, 2002).

Çizelge 3'te de görüldüğü gibi en yüksek yağ ve yakıt enerjisi değerleri geleneksel toprak işleme yönteminde hesaplanmıştır. Bunu sırasıyla azaltılmış toprak işleme-1 yöntemi ve azaltılmış toprak işleme-2 yöntemi takip etmiştir. En düşük enerji tüketimi doğrudan ekim yönteminde gerçekleşmiştir. Uygulamalarda aynı traktör kullanılmıştır. Çalışmada birim alana harcanan tohum

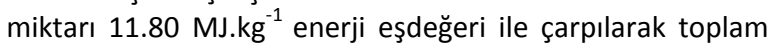
tohum enerjisi hesaplanmıştır (Singh, 2002).

Hesaplanan iş gücü değerlerinin enerji karşılığı olan 2.30 MJ. $\mathrm{h}^{-1}$ değeri ile çarpılarak toplam iş gücü enerji değerlerine dönüştürülmüştür (Yaldız ve ark, 1993).

Çizelge 3 incelendiğinde çapalama uygulamasının enerji değerinin toplam işgücü enerji değeri içerisinde en yüksek paya sahip olduğu görülmektedir. Bunun sebebi özellikle pamuk tarımında makina yerine insan işgücünün daha fazla tercih edilmesidir.

Denemelerde kullanılan gübre girdi miktarları hesaplanmıştır. Denemede gübreler eşit miktarda ve aynı ekipman kullanılarak yapılmıştır. Yapılan toprak analizleri sonucunda eksiklik görülmeyen potasyum besin elementi

uygulaması yapılmamış olup sadece azotlu ve fosforlu gübreler kullanılmıştır.

Kullanılan kimyasal ilaç miktarı değerleri ile kimyasal ilaç enerji eşdeğeri $101.20{\mathrm{MJ} . \mathrm{kg}^{-1}}^{-1}$ değeri çarpımı sonucu kimyasal ilaç enerjisi hesaplanmıştır. Denemede zirai mücadele tüm yöntemlerde aynı zamanda ve eşit miktarda uygulanmıştır. Tüm yöntemlerdeki kimyasal ilaç enerji değeri de eşit olarak bulunmuştur.

Sulama enerjisi, her yöntem için üretim periyodu boyunca yapılan sulamada kullanılan toplam su miktarı değerinin, sulama suyu enerji değeri olan $0.63 \mathrm{MJ}^{-3}$ değerinin çarpılmasıyla hesaplanmıştır. Denemede damla sulama yöntemi uygulanmış ve su sayacı ile verilen su miktarları ölçülmüştür (Yaldız ve ark, 1993).

Hasat verileri doğrultusunda pamuk kütlü verimi enerjisi hesaplanmıştır. Yöntemlere göre pamuk verimlerinin tekerrürler ortalamasının sonuçları verilmiştir. Çizelge 3 te pamuk enerji değeri birim alana verim ile pamuk enerji eşdeğeri olan $11.80 \mathrm{MJ} . \mathrm{kg}^{-1}$ değerinin çarpılmasıyla hesaplanmıştır (Yılmaz ve ark, 2005).

Çizelge 4'de hesaplanan enerji etkinlik göstergeleri topluca verilmiştir. En yüksek enerji oranı 4.38 ile geleneksel toprak işleme yönteminde hesaplanmıştır. Sonra sırasıyla 3.99 ile azaltılmış toprak işleme-2 yönteminde ve 3.93 ile doğrudan ekim yönteminde gerçekleşmiştir. En düşük enerji oranı ise 3.72 ile azaltılmış toprak işleme-1 yönteminde hesaplanmıştır. Özgül enerji değerlerinde ise en yüksek

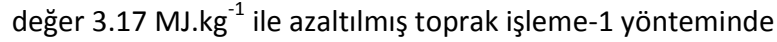
hesaplanmıştır. Net enerji verimi bakımından değerlendirildiğinde en yüksek net enerji verimi yaklaşık 52 bin MJ ile geleneksel toprak işleme yönteminde, sonra sırasıyla 42 bin MJ ile azaltılmış toprak işleme-2, 40 bin MJ ile doğrudan ekim ve 39 bin MJ ile azaltılmış toprak işleme1 yöntemlerinde gerçekleşmiştir. 
Çizelge 4. Pamuk Üretiminde Enerji Etkinlik Göstergeleri

\begin{tabular}{lcccc}
\hline & GTi & AZ1 & AZ2 & DE \\
\hline Enerji oranı & 4.38 & 3.72 & 3.99 & 3.93 \\
Özgül Enerji Değeri $\left(\mathrm{MJ} \mathrm{kg}^{-1}\right)$ & 2.70 & 3.17 & 2.96 & 3.00 \\
Enerji Üretkenliği değeri $\left(\mathrm{kg} \mathrm{MJ}^{-1}\right)$ & 0.37 & 0.32 & 0.34 & 0.33 \\
Net Enerji Verimi (MJ) & $52,472.34$ & $39,326.71$ & $41,733.31$ & $39,704.59$ \\
\hline
\end{tabular}

Enerji oranı yüksek olan toprak işleme yöntemlerinde daha etkin bir ürün yetiştirme modeli uygulandığı söylenebilir.

Enerji etkinliğinin önemli göstergelerinden birisi olan özgül enerji değeri ile birim ürünün ne kadar girdi enerjisi harcanarak üretildiği değerlendirilmektedir. Geleneksel toprak işleme yönteminde aynı üretim miktarını elde edebilmek için oransal olarak daha az enerji harcandığını söyleyebiliriz.

Enerji üretkenliği değeri yardımıyla, üretime giren enerjinin birim miktarı ile ne kadar ürün elde edildiği değerleriyle, enerjinin ürüne dönüşme süreci hakkında net kıyas düzlemi oluşturulabilmektedir.

Toplam enerji girdisi ve toplam enerji çıktısı yönünden elde edilen değerler istatistiki analize tabi tutulmuştur. Çizelge 5' te toplam enerji girdisi açısından yapılan istatistiki analiz sonuçları yer almaktadır. Yapılan varyans analizi sonucuna göre farklı toprak işleme yöntemleri arasındaki fark \%1 seviyesinde önemli bulunmuştur ve istatistiki gruplandırmada tüm yöntemler farklı grupta yer almıştır. Tekerrürler arasındaki fark önemsiz bulunmuştur. belirlenmektedir. Diğer bir ifadeyle, enerji üretkenliği Çizelge 5. Toplam enerji girdisi açısından yapılan istatistik analiz

\begin{tabular}{|c|c|c|}
\hline Yöntemler & Toplam Enerji Girdisi (KO) & İstatistiki Gruplar \\
\hline GTi & $15,545.81$ & $a$ \\
\hline AZ1 & $14,447.07$ & $\mathrm{~b}$ \\
\hline$A Z 2$ & $13,979.21$ & C \\
\hline $\mathrm{DE}$ & $13,564.15$ & $d$ \\
\hline $\mathrm{P}$ & \multicolumn{2}{|c|}{$* *$} \\
\hline VK & \multicolumn{2}{|c|}{0.87} \\
\hline AÖF 0.01 & \multicolumn{2}{|c|}{249.15} \\
\hline
\end{tabular}

Çalışmada elde edilen toplam enerji çıktısı değerleri de aynı şekilde istatistiki analize tabi tutulmuştur. Yapılan istatistiki değerlendirmede farklı toprak işleme uygulamalarının Çizelge 6. Toplam enerji çıktısı açısından yapılan istatistik analiz

\begin{tabular}{lll}
\hline Yöntemler & Toplam Enerji Çıktısı(KO) & İstatistiki Gruplar \\
\hline GTi & $59,943.61$ & a \\
AZ1 & $57,501.01$ & a \\
AZ2 & $59,667.10$ & a \\
DE & $53,661.68$ & a \\
P & ÖD & \\
VK & 7.86 & \\
AÖF 0.01 & - &
\end{tabular}

Yapılan tüm istatistiksel değerlendirmeler ışığında, toplam enerji çıktısı açısından yöntemler arasındaki farkın önemsiz çıkışı, toplam enerji girdisi değeri düşük olan yönteme teşvik etmektedir. Diğer bir deyişle azaltılmış toprak işleme ve doğrudan ekim yöntemlerinin tercih edilmesi, daha düşük enerji girdisi kullanmak suretiyle daha verimli ve ekonomik bir üretim yapmanın yolunu açmaktadır sonucuna varabiliriz.

\section{Tartışma}

Yapılan bu çalışma göstermiştir ki enerji etkinliğinin artırılması için öncelikle tarımsal üretimde kullanılan girdi miktarlarının azaltılması ve mekanizasyon uygulamalarının tarımsal üretimdeki payının artırılması büyük önem arz etmektedir.

Yapılan enerji analizinde en yüksek enerji girdi oranının kimyasal gübreden kaynaklı olduğu görülmektedir. Bunu sırasıyla yakıt-yağ, kimyasal ilaç ve sulama takip etmektedir. Buradan yola çıkarak tarımsal üretimde gübre, akaryakıt ve kimyasal ilaç kullanımının ne kadar önemli olduğunu söyleyebiliriz. Bu girdilerdeki optimal düzeylerin doğru yapıldığı tüm yöntemlerdeki ve tekerrürlerdeki fark istatistiki açıdan önemsiz çıkmıştır (Çizelge 6). tespit edilmesi ve doğru bir dozda kullanılması, gereksiz yada fazla gübre ve ilaç kullanımının önüne geçilmesi tarımda daha etkin bir enerji kullanımını sağlayabilecektir. Tarımda kullanılan suyun toplam enerji girdisinde payı oldukça büyüktür. Yaygın olarak kullanılan salma sulama yöntemleri yerine damla ya da yağmurlama sulama hem sulama suyunda ciddi bir su tasarrufu sağlayacağı gibi aynı zamanda enerji girdi değerlerinde suyun oransal ağırlığını da azaltacaktır.

Enerji kullanım etkinliğinde önemli olan bir diğer unsur da elde edilen ürün verim değerleridir. Verimi artıracak uygulamaların tercih edilmesi enerji verimliliğini artıracaktır. Koruyucu toprak işleme ve doğrudan ekim yöntemlerinde bu sistemin avantajlarının ortaya çıkmasının birkaç yıl sürebileceği bilinen bir gerçektir. Bu nedenle çalışma sonuçlarında ortaya çıkan maliyet ve verim değerlerindeki dezavantaj ilerleyen yıllarda avantaja dönüşerek daha yüksek verim ve daha düşük maliyet değerleri ile enerji etkinliği daha yüksek üretim modeli geliştirmek mümkün olabilecektir. 
Öte yandan çalışmada elde edilen sonuçlara göre; doğrudan ekim yönteminde başarıya ulaşılmasını sağlayan en önemli etkenlerden bir tanesi de yabancı otlarla etkin bir mücadelenin sağlanmasıdır. Pamuk tarımında, hem geleneksel toprak işleme yönteminde, hem de diğer toprak işleme yöntemlerinde çapalama kaynaklı insan işgücü gereksinimi önemli bir yer tutmaktadır. Yabancı ot kontrolünün tam manasıyla yapılamaması insan işgücü gereksinimini artırmakta, bu da verimliliği düşürmektedir.

Özellikle doğrudan ekim yönteminde, yabancı ot kontrolünün düzgün yapılmadığı durumlarda daha fazla insan işgücü kullanılmakta ve daha yüksek enerji girdisine sebep olmaktadır.

Sonuç olarak; gerekli tarımsal işlemlerin doğru şekilde ve doğru zamanda yapıldığı takdirde, doğrudan ekim ve azaltılmış toprak işleme yöntemlerinin rahatılıkla uygulanabileceğini söyleyebiliriz.

Bugüne kadar yapılan çalışmalarda elde edilen sonuçlardan yola çıkarak, pamuk tarımında, toprak işlemede doğru ekipman seçiminin yapılması, ekim öncesinden başlanarak yapılan yabancı ot mücadelesinin zamanında yapılması ve toprak analizi ile optimum gübre dozlarının belirlenerek fazla gübre kullanımının önüne geçilmesi suretiyle, hem çalışmanın yürütüldüğü Menemen bölgesinde, hem de ülkemizdeki diğer pamuk alanlarında daha karlı bir üretim yapmak mümkündür.

\section{KAYNAKLAR}

Anonim (2005) 2004 Yllı Faaliyet Raporu. Nazilli Pamuk Araştırma Enstitüsü, Aydın.

Anonim (2016) 2015 Yılı Pamuk Raporu. T.C. Gümrük ve Ticaret Bakanlığı Kooperatifçilik Genel Müdürlüğü, Ankara.

Aykas E, Önal i (1999) Effects of Different Tillage Seeding and Weed Control Methods on Plant Growth and Wheat Yield. 7. International Congress on
Mechanization and Energy in Agriculture, 26-27 May 1999, Adana, 119-124.

Çelik N, (2000) Tarımda Girdi Kullanımı ve Verimliliğe Etkisi. DPT Uzmanlık Tezleri, Yayın No: DPT: 2521, 154 Sayfa, Ankara.

Gözübüyük Z, Çelik A, Öztürk I, Demir O, Adıgüzel MC (2012) Buğday Üretiminde Farklı Toprak İşleme - Ekim Sistemlerinin Enerji Kullanım Etkinliği Yönünden Karşılaştırılması. Tarım Makinaları Bilimi Dergisi, 8 (1): 25-34.

Pirinççioğlu N (1988) Tarım Sektöründe Verimlilik (19701985 Dönemi). MPM, Yayın No:365, Ankara.

Reis M (2016) Tarımsal Verimlilik ve Ekonomik Gelişme. http://www.ufukotesi.com/yazdir.asp?yazi_no=20020 747 (Erişim Tarihi: 26/06/2016)

Singh JM (2002) On Farm Energy Use Pattern In Different Cropping Systems in Haryana, India. Master of Science, International Institute of Management University of Flensburg, Germany.

TOPRAKSU (1971) Menemen Ovası Temel Toprak Etüdü. Topraksu Genel Müdürlüğü Toprak ve Etüd Haritalama Dairesi Raporları, Seri No: 24, Ankara.

UTAEM (2016) Menemen Hidrometeoroloji Rasat Verileri Yıllığı, İzmir.

Yalçın H, Aykas E, Evrenosoğlu M (2003) Koruyucu Tarım ve Koruyucu Toprak İşleme Ege Üniversitesi Ziraat Fak. Dergisi, 153-160 İzmir.

Yaldiz O, Ozturk HH, Zeren Y, Bascetincelik A (1993) Energy Use in Field Crops Of Turkey. 5. International Congress of Agricultural Machinery and Energy, Kusadasi, Turkey.

Yılmaz I, Akcaoz H, Ozkan B (2005) An Analysis of Energy Use and Input-Output Costs for Cotton Production in Turkey. Renewable Energy, 30:145-55. 